\title{
Die Ritteratur
}

\author{
Dez neunzehnten $\mathfrak{T a h h a n d e r t z . ~}$
}

\author{
Dritter Band.
}





\section{Die Ritteratur}

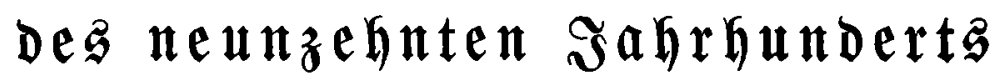

in

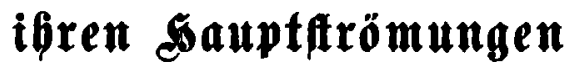

barge itellt

von

Gíarg Brandeb.

Dritter Band.

Die Reaftion in Franfreid.

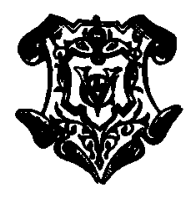

Peipzig,

Berlag von Beit \& Eomp.

1898. 


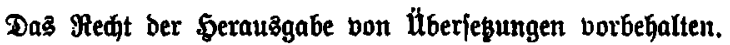

Irud von gRebger \& 2 ittig in seipgig. 